\title{
Knockdown of ephrin receptor A7 suppresses the proliferation and metastasis of A549 human lung cancer cells
}

\author{
RONGHUI LI ${ }^{1}$, YINGYAN SUN ${ }^{2}$, AIYING JIANG $^{3}$, YAN WU $^{4}$, CHENGWEI LI $^{1}$, \\ MINGCHUN JIN $^{1}$, HAIRUN YAN ${ }^{1}$ and HONG JIN ${ }^{1}$ \\ Departments of ${ }^{1}$ Clinical Laboratory, ${ }^{2}$ Ultrasonography and ${ }^{3}$ Pneumology, Hongqi Hospital, Mudanjiang Medical University; \\ ${ }^{4}$ Department of Medical Research Center, Mudanjiang Medical University, Mudanjiang, Heilongjiang 157011, P.R. China
}

Received February 6, 2015; Accepted November 18, 2015

DOI: $10.3892 / \mathrm{mmr} .2016 .4904$

\begin{abstract}
Previous studies have demonstrated that ephrin (Eph) family receptor tyrosine kinases and ligands promote cancer growth, invasion and metastasis. In addition, it has been reported that Eph receptor A7 (EphA7) is transcriptionally activated in lung cancer; however, the effects of silencing EphA7 expression on the growth of lung cancer cells, and the underlying molecular mechanisms, have yet to be determined. Therefore, the present study aimed to investigate whether silencing EphA7 with small interfering (si)RNA could induce apoptosis in non-small cell lung cancer (NSCLC) cells. Furthermore, the effects of siEphA7 on cell migration and invasion were evaluated using Transwell assays. The mechanisms underlying the effects of siEphA7 on the tumorigenic properties of A549 cells were also examined. The results of the present study demonstrated that transfection with siEphA7 inhibited the proliferation, migration and invasion of A549 cells. In addition, siEphA7 significantly increased the protein expression levels of B-cell lymphoma 2 (Bcl-2)-associated X protein and caspase-3, and decreased the protein expression levels of Bcl-2, thus suggesting that siEphA7 was able to induce apoptosis via the intrinsic apoptotic pathway. In addition, the expression levels of phosphatase and tensin homolog (PTEN) were significantly upregulated, and the expression levels of total AKT were not altered, whereas the levels of phosphorylated-AKT were reduced. These findings indicated that EphA7 may have an important role in the pathogenesis of NSCLC by regulating PTEN expression via the PTEN/AKT pathway. Silencing EphA7 may provide a novel approach for the treatment of NSCLC.
\end{abstract}

Correspondence to: Professor Hong Jin, Department of Clinical Laboratory, Hongqi Hospital, Mudanjiang Medical University, 530 Diming Road, Mudanjiang, Heilongjiang 157011, P.R. China E-mail: jinhong125@sina.cn

Key words: EphA7, invasion, PTEN, apoptosis, lung cancer

\section{Introduction}

Lung cancer is one of the most common types of occupational cancer, and is the leading cause of cancer-associated mortality worldwide (1). According to its histological characteristics, lung cancer is defined as either non-small cell lung cancer (NSCLC) or small cell lung cancer. Approximately $80 \%$ of lung cancer cases are considered to be NSCLC, which comprises adenocarcinoma, squamous cell carcinoma and large cell carcinoma. It is well known that air pollution and tobacco smoke, as well as numerous other factors, increase the incidence of lung cancer; however, the mechanisms underlying lung cancer formation remain largely unknown (2). Furthermore, in the majority of clinical cases, lung cancer is metastatic, which is typically incurable. Metastasis is one of the most lethal characteristics of cancer, and is responsible for $\sim 90 \%$ of human cancer-associated mortality (3). The metastasis of lung cancer is a complex process, which includes cellular migration, local invasion and dissemination. Blocking one of the steps of metastasis may effectively prevent secondary tumors from spreading in the body $(4,5)$.

Receptor tyrosine kinases (RTKs), which are well known as the major regulators of cellular growth, are associated with the regulation of cell proliferation, differentiation and migration (6). The ephrin (Eph) receptors represent the largest family of RTKs and interact with ligands known as ephrins. Previous pre-clinical and laboratory studies have demonstrated that the function of RTKs is associated with tumor growth, metastasis and neovascularization $(7,8)$. Based on sequence homology, structure and binding affinity, Eph receptors are subdivided into two types: A and B (9). Class A receptors are tethered to glycosylphosphatidylinositol-linked class A ephrins, whereas class $\mathrm{B}$ receptors are tethered to ephrin-B ligands, which comprise a transmembrane domain and a short cytoplasmic tail. Overall, 14 receptors (nine class A and five class B) and eight ligands (five class A and three class B) have been detected in the human genome. Previous studies have demonstrated that Eph receptor and ephrin genes are differentially expressed in human tumors, including neuroblastoma, prostate cancer and breast cancer (10-12).

Eph receptor A7 (EphA7), which was formerly known as Mdk1/Ebk/Ehk, is highly conserved in vertebrates from fish to humans (13). Hafner et al (14) reported that EphA7 
is highly expressed in kidney vasculature. In addition, the mRNA expression levels of EphA7 are markedly upregulated in hepatocellular carcinoma, as compared with in healthy liver tissue, and EphA7 is transcriptionally activated in lung cancer (15). Furthermore, overexpression of EphA7 is frequently detected in younger patients, and in patients with advanced gastric carcinoma (16). However, little is currently known regarding the role of EphA7 in the development of NSCLC. The present study silenced EphA7 expression using EphA7-specific small interfering (si)RNA, and examined the effects on cell viability and apoptosis. In addition, alterations in cell migration and invasion were detected. The results of the present study provided evidence suggesting that siEphA7 exerted anticancer activity in A549 human NSCLC cells via proapoptotic mechanisms.

\section{Materials and methods}

Cell culture and siRNA transfection. The A549 human NSCLC cell line was purchased from the Institute of Biochemistry and Cell Biology, Chinese Academy of Science (Shanghai, China). The cells were cultured at $37^{\circ} \mathrm{C}$ in Dulbecco's modified Eagle's medium (DMEM; Shanghai Huiying Biotechnology Co., Ltd., Shanghai, China) supplemented with $10 \%$ fetal bovine serum (FBS; Shanghai Huiying Biotechnology Co., Ltd.), 100 U/ml penicillin and $100 \mu \mathrm{g} / \mathrm{ml}$ streptomycin (Shanghai Huiying Biotechnology Co., Ltd.). Subsequently, $70-80 \%$ of the cells were transferred to 96-well plates and cultured in fresh medium without antibiotics. X-treme ${ }^{\mathrm{TM}}$ GENE siRNA Transfection Reagent (Roche Diagnostics, Basel, Switzerland) was used to transfect the cells with siEphA7 (Shanghai GenePharma Co., Ltd., Shanghai, China; sequence, 5'-GUGGGAAGUUAUGUC UUAUTTAUAAGACAUAACUUCCCACTT-3') or negative control siRNA (Shanghai GenePharma Co., Ltd.; sequence, 5'-UUCUCCGAACGUGUCACGUTTACGUGACACGUC

CGGAGAATT-3'). The transfection concentration determined for use by transfection efficiency testing was $50 \mathrm{nM}$ siEphA7, transfection was conducted for $24 \mathrm{~h}$ at $37^{\circ} \mathrm{C}$. A549 cells were used as the untransfected control group.

Cell viability assay. The colorimetric 3-(4,5-dimethylthiazol-2-yl)-2,5-diphenyl tetrazolium bromide (MTT) assay (Beyotime Institute of Biotechnology, Haimen, China) was used to assess the viability of cells cultured in 96-well plates by measuring mitochondrial dehydrogenase activity. The MTT assay is based on the notion that viable cells, but not dead cells, can reduce MTT. Following siRNA transfection, the cells were incubated with $10 \mu \mathrm{l}$ MTT $(0.5 \mathrm{mg} / \mathrm{ml})$ at $37^{\circ} \mathrm{C}$ for $4 \mathrm{~h}$. The purple formazan crystals were then dissolved using $100 \mu 1$ dimethyl sulfoxide. The absorbance was subsequently measured at $490 \mathrm{~nm}$ using an 340 AT Easy Microplate Reader (SLT Lab Instruments GmbH, Salzburg, Austria).

Reverse transcription-quantitative polymerase chain reaction (RT-qPCR) analysis. Cellular mRNA expression levels of EphA7 were determined using RT-qPCR. Total RNA $(1 \mu \mathrm{g})$ was extracted from each sample of cells using TRIzol (Invitrogen; Thermo Fisher Scientific, Inc., Waltham, MA, USA), and was used to generate cDNA using M-MLV Reverse
Transcriptase (Promega Corporation, Madison, WI, USA). The cycling conditions were as follows: Initial denaturation at $25^{\circ} \mathrm{C}$ for $10 \mathrm{~min} ; 37^{\circ} \mathrm{C}$ for $120 \mathrm{~min} ; 85^{\circ} \mathrm{C}$ for $5 \mathrm{~min}$; the temperature was dropped to $4^{\circ} \mathrm{C}$ and the product was reached at $20^{\circ} \mathrm{C}$. qPCR was conducted using SYBR Green PCR Master Mix (Applied Biosystems; Thermo Fisher Scientific, Inc.), and the PCR cycling conditions were as follows: Initial denaturation at $95^{\circ} \mathrm{C}$ for $10 \mathrm{~min}$, followed by 40 cycles at $95^{\circ} \mathrm{C}$ for $15 \mathrm{sec}$, $60^{\circ} \mathrm{C}$ for $30 \mathrm{sec}$ and $72^{\circ} \mathrm{C}$ for $30 \mathrm{sec}$, followed by a final extension step at $72^{\circ} \mathrm{C}$ for $10 \mathrm{~min}$. The PCR primers used were as follows: Sense, 5'-CTAATGTTGGATTGTTGGCAAAAG-3' and antisense, 5'-TTGATCCAGAAGAGGGCTTATTG-3' for EphA7 and sense, 5'-AAGAAGGTGGTGAAGCAGGC-3' and antisense, 5'-TCCACCACCCAGTTGCTGTA-3' for GAPDH. A 7500 Fast Real-Time PCR system (Applied Biosystems; Thermo Fisher Scientific, Inc.) was used for cDNA amplification, with routine product checking using dissociation curve software (QuantStudio ${ }^{\mathrm{TM}}$ Real-Time PCR software, version 2.0.6; Applied Biosystems; Thermo Fisher Scientific, Inc.). Transcript quantities were compared using a relative quantification method. The amount of detected mRNAs was normalized to the amount of the endogenous control GAPDH. The relative value to the control sample was determined using the $2^{-\Delta \Delta \mathrm{Cq}}$ method (17).

Terminal deoxynucleotidyl-transferase-mediated dUTP nick end labeling (TUNEL) staining assay. The cells were fixed in $4 \%$ paraformaldehyde (Beijing Dingguo Changsheng Biotechnology Co., Ltd., Beijing, China) and pretreated with ethanol, proteinase K (Tiangen Biotech Co., Ltd., Beijing, China), Triton X-100 (Beijing Solarbio Science and Technology Co., Ltd., Beijing, China), and pepsin (Shanghai Haoran Bio Technologies Co., Ltd., Shanghai, China). Following washing in PBS three times, the samples were treated with the TUNEL reaction mixture and TUNEL Dilution buffer (In Situ Cell Death Detection kit; Roche Diagnostics, Basel, Switzerland) at a ratio of 1:9, and incubated in a humidified chamber for $1 \mathrm{~h}$ at $37^{\circ} \mathrm{C}$. After washing in phosphate-buffered saline (PBS), anti-digoxigenin peroxidase conjugate (Roche Diagnostics) was added, and incubation continued in a humidified chamber for $30 \mathrm{~min}$ at room temperature. The samples were washed with PBS and the nuclei were stained with DAPI (Roche Molecular Diagnostics, Pleasanton, CA, USA) for $5 \mathrm{~min}$ at room temperature. The number of total cells and TUNEL-positive cells were automatically counted using Image-Pro Plus (Media Cybernetics, Inc., Rockville, MD, USA), in order to calculate the apoptotic rate, which was defined as the ratio of apoptotic cells to total cells.

Transwell migration and invasion assays. The migration and invasion assays were carried out using Transwell plates (EMD Millipore, Billerica, MA, USA). The filter surfaces ( $8 \mu \mathrm{m}$ pore size) of the Transwell plates were uniformly coated with $25 \mathrm{mg}$ Matrigel (BD Biosciences, Franklin Lakes, NJ, USA) overnight at $4^{\circ} \mathrm{C}$ prior to experimentation. The lower chamber was filled with culture medium supplemented with $10 \%$ FBS. The A549 cells were carefully transferred onto the matrigel-coated (BD Biosciences, Franklin Lakes, NJ, USA) upper surface of the chamber at a seeding density of $1-4 \times 10^{5}$ cells per flask (Corning Incorporated, Corning, NY, USA). 
A

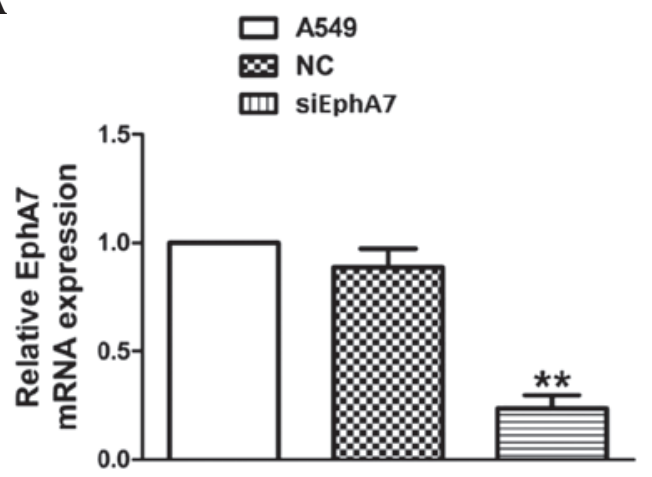

B
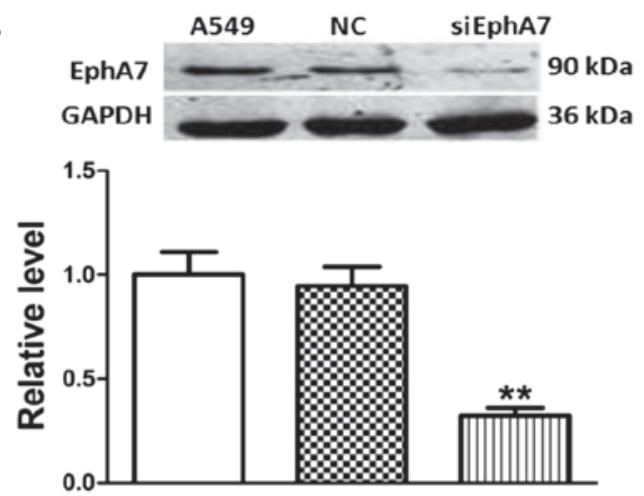

Figure 1. Transfection with ephrin receptor A7 (EphA7)-specific small interfering RNA (siEphA7) silenced EphA7 (A) mRNA and (B) protein expression levels in A549 non-small cell lung cancer cells, as detected by quantitative polymerase chain reaction and western blotting, respectively; $n=6$. Data are presented as the mean \pm standard error of the mean. ${ }^{* *} \mathrm{P}<0.01$ vs. the A459 control group. GAPDH, glyceraldehyde 3-phosphate dehydrogenase; NC, negative control.

Following a $24 \mathrm{~h}$ incubation at $37^{\circ} \mathrm{C}$, the filter was gently removed, and the upper surface was wiped to remove the attached cells. The cells that had invaded through the Matrigel and attached to the lower surface of the filter were fixed with 4\% paraformaldehyde and stained with Giemsa (GefanBio Co. Ltd., Shanghai, China). Three replicates were conducted for each condition. A total of 15 random fields in each replicate were selected and the number of cells was counted using an Olympus CKX41 inverted microscope (Olympus Corporation, Tokyo, Japan). The results are presented as the ratio of invasive cells relative to the invasive cells in the control conditions (cells seeded in serum-free media, which invaded towards DMEM containing $10 \%$ FBS). Cells that had invaded to the lower sides of the Transwell were fixed with $4 \%(\mathrm{w} / \mathrm{v})$ paraformaldehyde and stained using $0.05 \%$ crystal violet (Amresco, LLC, Solon, $\mathrm{OH}, \mathrm{USA}$ ) for cell counting as described above. Cells on the upper side of the membrane were scraped off and cells that had migrated to the lower side of the membrane were fixed in $4 \%$ paraformaldehyde, stained with $0.1 \%$ crystal violet for $30 \mathrm{~min}$ at room temperature, and washed 3 times with PBS.

Western blot analysis. Total protein was extracted from the cells for protein immunoblotting using radioimmunoprecipitation buffer (Beyotime Institute of Biotechnology) and protease inhibitors (Shenergy Biocolor, Shanghai, China) and the protein concentration was quantified using a bicinchoninic acid assay (Beyotime Institute of Biotechnology). Briefly, protein samples $(80 \mu \mathrm{g})$ were separated by $10 \%$ sodium dodecyl sulfate-polyacrylamide gel electrophoresis and blotted onto nitrocellulose membranes (Beyotime Institute of Biotechnology). The blots were blocked with 5\% non-fat milk for $2 \mathrm{~h}$ at room temperature, and then incubated with the following primary antibodies: Rabbit polyclonal anti-EphA7 IgG (1:1,000; Santa Cruz Biotechnology, Inc., Dallas, TX, USA; cat. no. sc-918), rabbit polyclonal anti-B-cell lymphoma 2 (Bcl-2; 1:1,000; Cell Signaling Technology, Inc., Danvers, MA, USA; cat. no. 2876), rabbit polyclonal anti-Bcl-2-associated X protein (Bax; 1:1,000; Cell Signaling Technology, Inc.; cat. no. 2774), rabbit polyclonal anti-caspase-3 (1:1,000; Cell Signaling Technology, Inc.; cat. no. 9662), rabbit polyclonal anti-phosphatase and tensin homolog (PTEN; 1:1,000; Cell Signaling Technology, Inc.; cat. no. 9552), rabbit polyclonal
anti-AKT (1:1,000; Cell Signaling Technology, Inc.; cat. no. 9272) and anti-phosphorylated (p)-AKT (1:1,000; Cell Signaling Technology, Inc.; cat. no. 9271), and anti-GAPDH (1:1,000; Santa Cruz Biotechnology, Inc.; cat. no. sc-48166) in $\mathrm{PBS}$ at $4^{\circ} \mathrm{C}$ overnight. Subsequently, the membranes were washed with PBS containing $0.1 \%$ Tween and incubated with Alexa Fluor ${ }^{\circledR} 700$-conjugated goat anti-mouse $\operatorname{IgG}(1: 8,000$; Invitrogen; Thermo Fisher Scientific, Inc.; cat. no. A-21036) and IRDye ${ }^{\circledR} 800 \mathrm{CW}$ goat anti-rabbit IgG $(1: 8,000$; LI-COR Biosciences, Lincoln, NE, USA) for $1 \mathrm{~h}$ at room temperature. The bands were visualized using an imaging system (LI-COR Biosciences), and semi-quantified using Odyssey v1.2 software (LI-COR Biosciences) by measuring intensity (area x optical density). GAPDH was used as an internal control. The results were expressed as fold changes by normalizing the data to the control values.

Statistical analysis. All data are expressed as the mean \pm standard error of mean. Statistical analyses, including an unpaired two-tailed Student's t-test and one-way analysis of variance followed by the Bonferroni's multiple comparison post hoc test were carried out using GraphPad Prism v6.0 (GraphPad Software, Inc., La Jolla, CA, USA). P $<0.05$ was considered to indicate a statistically significant difference.

\section{Results}

Silencing EphA7 with siEphA7 suppresses the viability of A549 cells. To confirm the silencing effect of siEphA7 on EphA7 expression, the EphA7 mRNA expression levels were detected using RT-qPCR. As shown in Fig. 1A, as compared with the control group, there were no significant alterations in the non-specific siRNA-transfected control group, however the EphA7 mRNA expression levels were significantly decreased following transfection with siEphA7 for $24 \mathrm{~h}$. Furthermore, western blotting demonstrated that siEphA7 also downregulated the protein expression levels of EphA7 (Fig. 1B). These results indicate that EphA7 expression was significantly silenced post-transfection with siEphA7.

An MTT viability assay was conducted to determine the effects of siEphA7 on cell viability. As shown in Fig. 2A, transfection with siEphA7 for $24 \mathrm{~h}$ resulted in a $\sim 50 \%$ reduction 


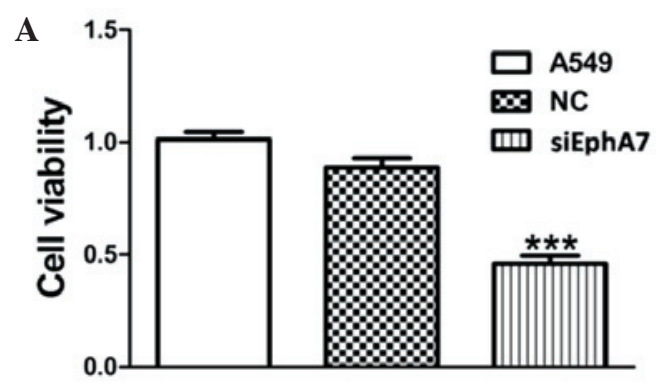

B
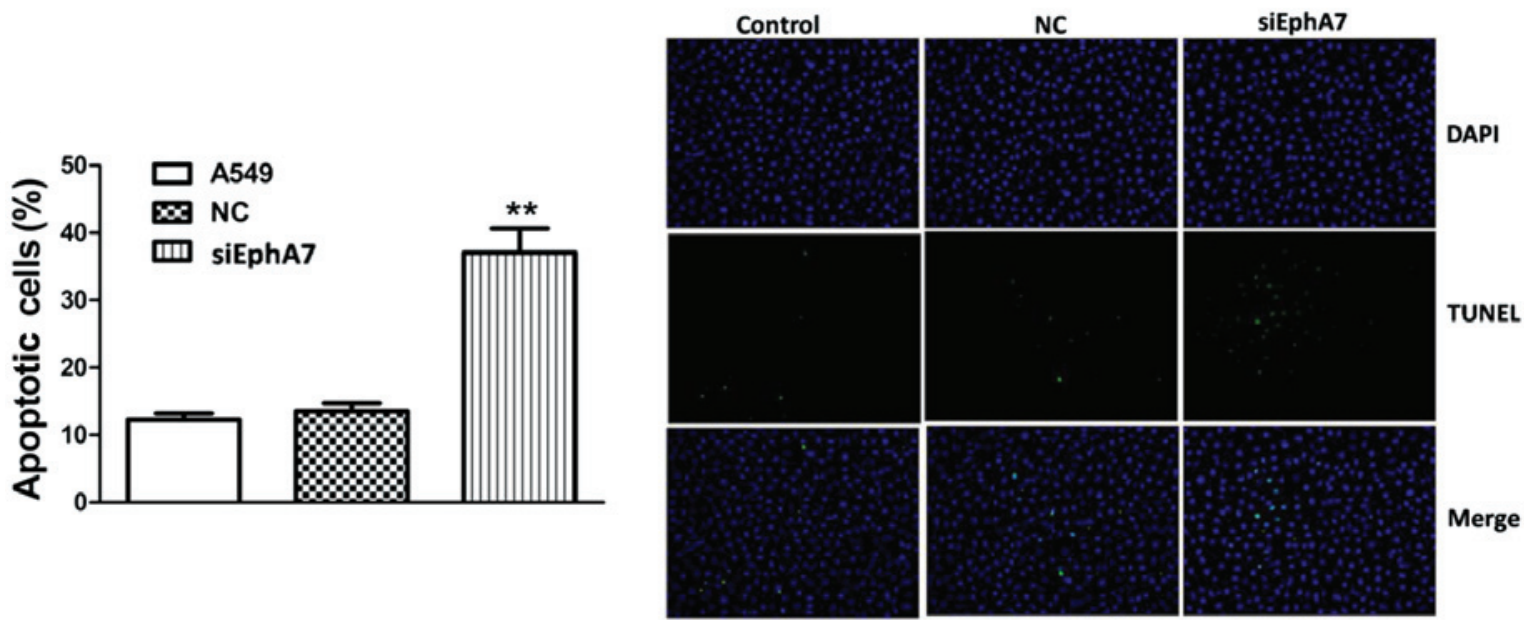

Figure 2. Silencing ephrin receptor A7 (EphA7) EphA7 with small interfering RNA (siEphA7) (A) inhibited viability and (B) induced apoptosis of A549 non-small cell lung cancer cells; $\mathrm{n}=4$. Data are presented as the mean \pm standard error of the mean. ${ }^{* *} \mathrm{P}<0.01,{ }^{* * * *} \mathrm{P}<0.001$ vs. the A459 control group. NC, negative control; TUNEL, terminal deoxynucleotidyl-transferase-mediated dUTP nick end labeling; DAPI, 4',6-diamidino-2-phenylindole.

A
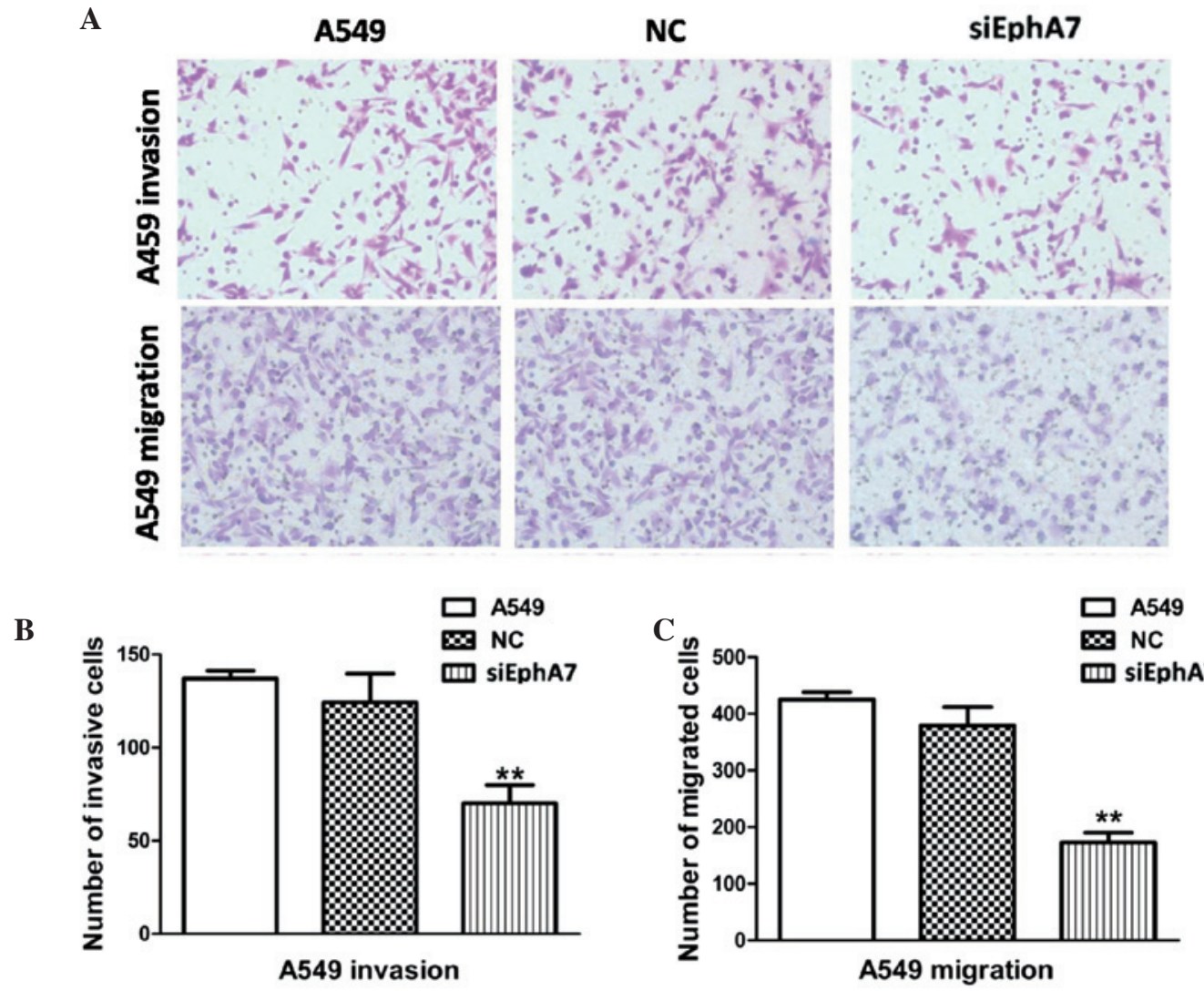

Figure 3. Effects of Ephrin receptor A7-specific small interfering RNA (siEphA7) on (A) migration and invasion in A549 non-small cell lung cancer cells (magnification, 200x). Average number of (B) invasive and (C) migrated cells from three independent experiments; $\mathrm{n}=3$. Data are presented as the mean \pm standard error of the mean. ${ }^{* *} \mathrm{P}<0.01$ vs. the A459 control. NC, negative control. 
A
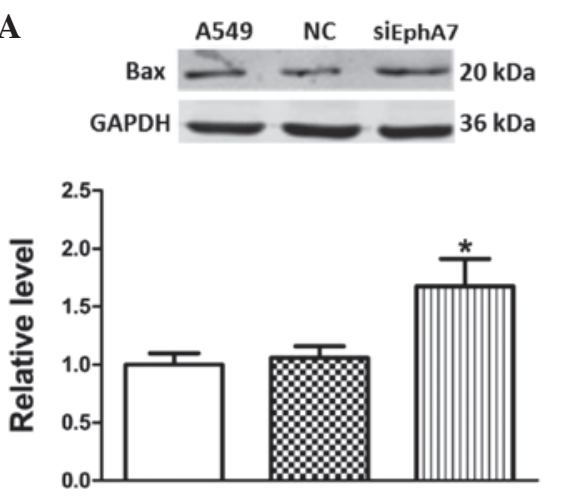

B
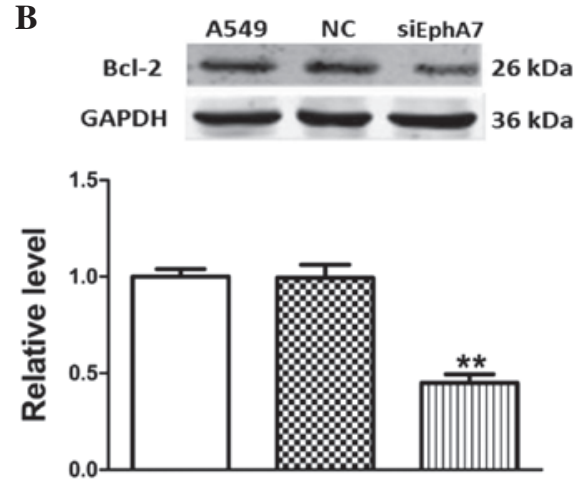

C
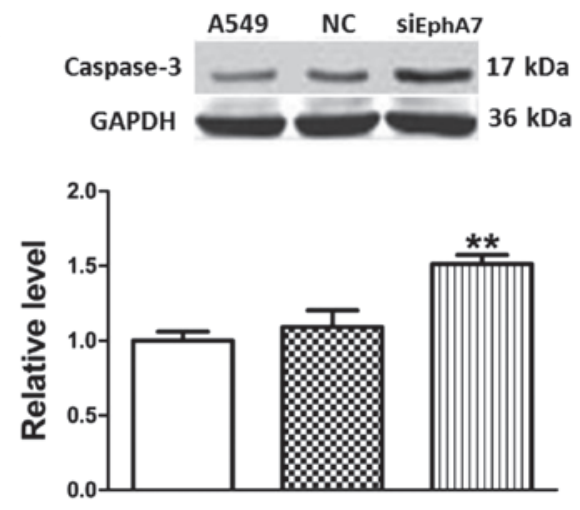

Figure 4. Effects of Ephrin receptor A7-specific small interfering RNA (siEphA7) on the expression levels of apoptosis-related proteins: (A) B-cell lymphoma 2 (Bcl-2)-associated X protein (Bax), (B) Bcl-2, and (C) caspase-3; $\mathrm{n}=6$. Data are presented as the mean \pm standard error of the mean. ${ }^{*} \mathrm{P}<0.05,{ }^{* *} \mathrm{P}<0.01 \mathrm{vs}$. the A459 control group. GAPDH, glyceraldehyde 3-phosphate dehydrogenase; NC, negative control.

A

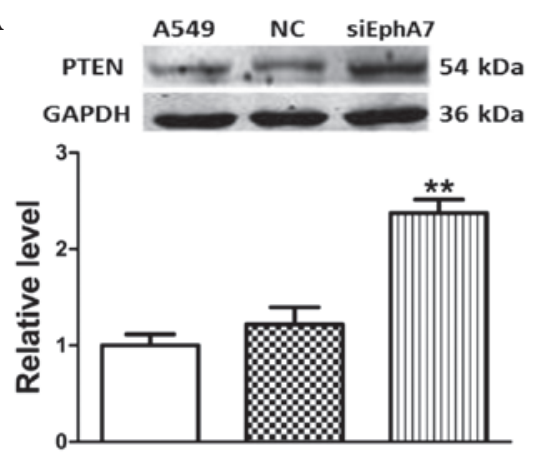

B
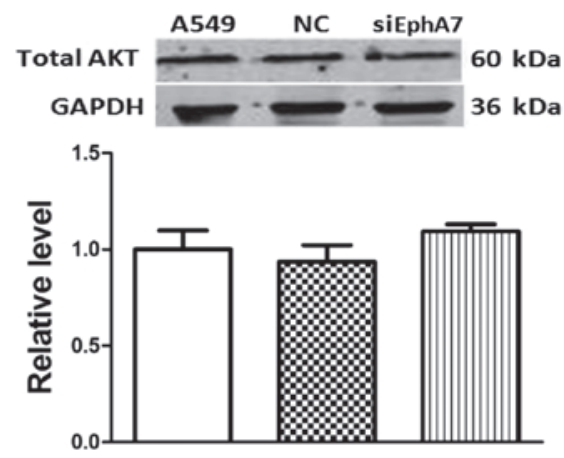

C
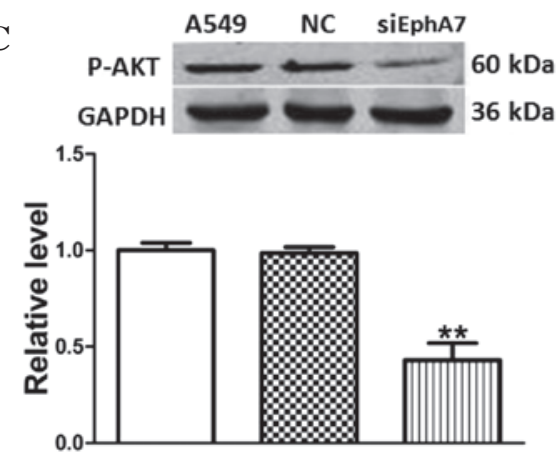

Figure 5. Effects of Ephrin receptor A7-specific small interfering RNA (siEphA7) on the phosphatase and tensin homolog (PTEN)/AKT signaling pathway in A549 cells. (A) siEphA7 upregulated PTEN protein expression. The effects of siEphA7 on (B) total AKT and (C) phosphorylated (P)-AKT expression; n=6. Data are presented as the mean \pm standard error of the mean. ${ }^{* *} \mathrm{P}<0.01$ vs. the $\mathrm{A} 459$ control group. GAPDH, glyceraldehyde 3-phosphate dehydrogenase; $\mathrm{NC}$, negative control.

in proliferation rate, as compared with the control group. Furthermore, the results of the MTT assay were confirmed by
TUNEL assay. Transfection with siEphA7 markedly induced apoptosis in A549 cells (Fig. 2B). These results suggest that 
EphA7 has a key role in the regulation of lung cancer cell growth.

siEphA7 alters the migration and invasion of A549 cells. An important factor in tumor metastasis and progression is the ability of tumor cells to invade beyond the limitations of the primary tumor environment. Therefore, a Transwell assay was conducted, in order to investigate the ability of cells to invade through a biological matrix. As shown in Fig. 3A and B, transfection with siEphA7 markedly inhibited the ability of A549 cells to invade through the Matrigel-coated filter; the rate of invasion of A549 cells was decreased by $>50 \%$, as compared with the control group.

To explore whether the decreased invasiveness mediated by siEphA7 was associated with cell motility, the effects of siEphA7 on cell migration were detected. As shown in Fig. 3A and C, the migratory capabilities of the A549 cells transfected with siEphA7 were reduced by $\sim 62.9 \%$, as compared with the control group. These results indicate that knockdown of EphA7 significantly inhibits cell invasion and migration in vitro.

Effects of siEphA7 on the expression levels of apoptosis-associated proteins. Alterations in the expression levels of apoptosis-inducing signaling molecules were evaluated in A549 cells post-transfection with siEphA7 for $24 \mathrm{~h}$. The Bcl-2 family proteins, which include pro-apoptotic Bax and anti-apoptotic Bcl-2, are known regulators of apoptotic pathways (18). Therefore, in the present study, Bcl-2 and Bax protein expression levels were detected, in order to investigate whether these proteins were associated with siEphA7-induced apoptosis. As compared with the control group, transfection with siEphA7 upregulated Bax protein expression levels (Fig. 4A), and significantly inhibited Bcl-2 protein expression levels (Fig. 4B). The inhibition rate was $\sim 50 \%$. These results indicate that siEphA7 induced apoptosis via regulation of the Bcl-2 family protein-mediated mitochondrial pathway.

Since caspase-3 is well established as a major caspase, and its activation ultimately leads to cell death (19), it is often used to detect apoptosis. The present study evaluated whether siEphA7-induced apoptosis was associated with alterations in caspase-3 protein expression. Caspase-3 protein expression levels were significantly upregulated ( 1.5-fold) in A549 cells post-transfection with siEphA7 (Fig. 4C). These results indicate that siEphA7 induced apoptosis via upregulation of caspase-3 protein expression.

Silencing EphA7 regulates the PTEN/AKT signaling pathway in A549 cells. PTEN, which is an important tumor suppressor that is mutated in various malignancies, is a central negative regulatory factor of the AKT pathway (20). In order to investigate the effects of EphA7 knockdown on the activity of the PTEN/AKT signaling pathway in A549 cells, the protein expression levels of PTEN, AKT and P-AKT were measured using western blotting. The protein expression levels of PTEN were significantly higher in A549 cells transfected with siEphA7, as compared with the control group (Fig. 5A). In addition, the protein expression levels of total AKT were unchanged between the groups, whereas the expression levels of P-AKT were reduced (Fig. 5B and C). These results suggest that the inhibition of EphA7 may inhibit the AKT signaling pathway via upregulation of PTEN in A549 cells.

\section{Discussion}

The present study, to the best of our knowledge, is the first to demonstrate that silencing EphA7 with siEphA7 inhibits the viability, invasion and migration of A549 cells. In addition, the expression levels of the apoptosis-inducing signaling molecules Bax and caspase- 3 were increased, whereas the expression levels of Bcl-2 were decreased. Furthermore, the AKT signaling pathway was inhibited via upregulation of PTEN in A549 cells. These findings indicated that the proliferation and metastasis of NSCLC cells may be altered at the molecular level. The results of the present study help improve our understanding regarding the proapoptotic mechanisms underlying the anticancer effects of siEphA7, thus suggesting that knockdown of EphA7 has potential therapeutic value.

Previous studies have demonstrated that the regulation of Eph receptors and ephrin ligands is associated with tumor growth, metastasis and adverse outcomes (21-23). It has been reported that EphA7 is highly expressed in kidney vasculature (14), and the expression of EphA7 is transcriptionally activated in lung cancer (15). However, few studies have clarified the role of EphA7 in tumor pathogenicity. Therefore, in the present study, EphA7 expression was silenced using siEphA7, and the effects on cell viability and apoptosis were detected. Results of the MTT and TUNEL assays demonstrated that knockdown of EphA7 with siEphA7 significantly decreased cell viability and promoted apoptosis. Therefore, the present study aimed to further investigate the underlying molecular mechanisms associated with siEphA7-induced cell apoptosis.

$\mathrm{Bcl}-2$ is an antiapoptotic protein, whereas Bax is a proapoptotic protein, both of which belong to the Bcl-2 family, a group of proteins that regulate the permeability of the outer mitochondrial membrane (24). In addition, downregulation of Bcl-2 or upregulation of Bax may induce cell apoptosis and subsequently activate caspase-3 (25). Therefore, the present study examined the expression levels of apoptosis-associated proteins, including Bcl-2, Bax and caspase-3 in A549 NSCLC cells. Transfection with siEphA7 significantly downregulated the protein expression levels of Bcl-2 and upregulated the protein expression levels of Bax, which led to the activation of cell apoptosis. Furthermore, caspase-3 protein expression levels were increased. These results indicated that knockdown of EphA7 induced A549 cell apoptosis predominantly via the Bcl-2/Bax-dependent mitochondrial pathway. In addition, caspase-3 was also involved in the cell apoptosis.

In the present study, PTEN, AKT and P-AKT protein expression levels were detected by western blotting, in order to investigate whether silencing EphA7 led to inhibition of the activity of the PTEN/AKT signaling pathway. The results demonstrated that the expression levels of PTEN were markedly increased. In addition, a low phosphorylation level of AKT was observed. These results indicated that silencing EphA7 may downregulate the PTEN/AKT signaling pathway in NSCLC cells. Furthermore, it was hypothesized that the anticancer effects of EphA7 knockdown may not only by due to cell apoptosis, but also be due to effects on tumor invasion and metastasis. Transwell assays were performed in 
A549 NSCLC cells, and the results indicated that siEphA7 was able to regulate cell invasion and migration as a tumor suppressor. These results provide initial insights into the function of siEphA7 in regulating cell migration and invasion of NSCLC cells.

In conclusion, the results of the present study suggested that silencing EphA7 may exert potential tumor suppressive effects by targeting PTEN/AKT. In addition, siEphA7 had a crucial role in regulating the migration and invasion of NSCLC cells. The precise molecular mechanisms require further study; however, silencing EphA7 expression provides a novel insight into potential therapeutic strategies for the treatment of patients with lung cancer.

\section{References}

1. Jemal A, Bray F, Center MM, Ferlay J, Ward E and Forman D: Global cancer statistics. CA Cancer J Clin 61: 69-90, 2011.

2. Wang L, Xiong Y, Sun Y, Fang Z, Li L, Ji H and Shi T: HLungDB: An integrated database of human lung cancer research. Nucleic Acids Res 38 (Database Issue): D665-D669, 2010.

3. Inamura $\mathrm{K}$ and Ishikawa $\mathrm{Y}$ : Lung cancer progression and metastasis from the prognostic point of view. Clin Exp Metastasis 27: 389-397, 2010

4. Mihaljevic AL, Michalski CW, Friess H and Kleeff J: Molecular mechanism of pancreatic cancer - understanding proliferation, invasion, and metastasis. Langenbecks Arch Surg 395: 295-308, 2010.

5. Hoon DS, Ferris R, Tanaka R, Chong KK, Alix-Panabières C and Pantel K: Molecular mechanisms of metastasis. J Surg Oncol 103: 508-517, 2011.

6. van der Geer P, Hunter T and Lindberg RA: Receptor protein-tyrosine kinases and their signal transduction pathways. Annu Rev Cell Biol 10: 251-337, 1994.

7. Pasquale EB: Eph receptors and ephrins in cancer: Bidirectional signalling and beyond. Nat Rev Cancer 10: 165-180, 2010.

8. Matsumura Y, Umemura S, Ishii G, Tsuta K, Matsumoto S, Aokage K, Hishida T, Yoshida J, Ohe Y, Suzuki H, et al: Expression profiling of receptor tyrosine kinases in high-grade neuroendocrine carcinoma of the lung: A comparative analysis with adenocarcinoma and squamous cell carcinoma. J Cancer Res Clin Oncol 141: 2159-70, 2015.

9. Eph Nomenclature Committee: Unified nomenclature for Eph family receptors and their ligands, the ephrins. Cell 90: 403-404, 1997.

10. Kiyokawa E, Takai S, Tanaka M, Iwase T, Suzuki M, Xiang YY, Naito Y, Yamada K, Sugimura H and Kino I: Overexpression of ERK, an EPH family receptor protein tyrosine kinase, in various human tumors. Cancer Res 54: 3645-3650, 1994.
11. Tang XX, Zhao H, Robinson ME, Cohen B, Cnaan A, London W, Cohn SL, Cheung NK, Brodeur GM, Evans AE and Ikegaki N: Implications of EPHB6, EFNB2, and EFNB3 expressions in human neuroblastoma. Proc Natl Acad Sci USA 97: 10936-10941, 2000.

12. Walker-Daniels J, Coffman K, Azimi M, Rhim JS, Bostwick DG, Snyder P, Kerns BJ, Waters DJ and Kinch MS: Overexpression of the EphA2 tyrosine kinase in prostate cancer. Prostate 41: 275-280, 1999.

13. Taneja R, Thisse B, Rijli FM, Thisse C, Bouillet P, Dollé P and Chambon P: The expression pattern of the mouse receptor tyrosine kinase gene MDK1 is conserved through evolution and requires Hoxa-2 for rhombomere-specific expression in mouse embryos. Dev Biol 177: 397-412, 1996.

14. Hafner C, Schmitz G, Meyer S, Bataille F, Hau P, Langmann T, Dietmaier W, Landthaler M and Vogt T: Differential gene expression of Eph receptors and ephrins in benign human tissues and cancers. Clin Chem 50: 490-499, 2004.

15. Surawska H, Ma PC and Salgia R: The role of ephrins and Eph receptors in cancer. Cytokine Growth Factor Rev 15: 419-433, 2004.

16. Nakanishi H, Nakamura T, Canaani E and Croce CM: ALL1 fusion proteins induce deregulation of EphA7 and ERK phosphorylation in human acute leukemias. Proc Natl Acad Sci USA 104: 14442-14447, 2007.

17. Wu Z, Liu K, Wang Y, Xu Z, Meng J and Gu S: Upregulation of microRNA-96 and its oncogenic functions by targeting CDKN1A in bladder cancer. Cancer Cell Int 15: 107, 2015.

18. Suen DF, Norris KL and Youle RJ: Mitochondrial dynamics and apoptosis. Genes Dev 22: 1577-1590, 2008.

19. Slee EA, Adrain C and Martin SJ: Executioner caspase-3, -6, and -7 perform distinct, non-redundant roles during the demolition phase of apoptosis. J Biol Chem 276: 7320-7326, 2001.

20. Liu S, Cheng L,Bi X,Zhang X,Liu S,BaiX,LiF,Zhao AZ:Elevation of $\omega-3$ polyunsaturated fatty acids attenuates PTEN-deficiency induced endometrial cancer development through regulation of COX-2 and PGE2 production. Sci Rep 5: 14958.

21. Kinch MS, Moore MB and Harpole DH Jr: Predictive value of the EphA2 receptor tyrosine kinase in lung cancer recurrence and survival. Clin Cancer Res 9: 613-618, 2003.

22. Kataoka H, Igarashi H, Kanamori M, Ihara M, Wang JD, Wang YJ, Li ZY, Shimamura T, Kobayashi T, Maruyama K, et al: Correlation of EPHA2 overexpression with high microvessel count in human primary colorectal cancer. Cancer Sci 95: 136-141, 2004

23. Nakamura R, Kataoka H, Sato N, Kanamori M, Ihara M, Igarashi H, Ravshanov S, Wang YJ, Li ZY, Shimamura T, et al: EPHA2/EFNA1 expression in human gastric cancer. Cancer Sci 96: 42-47, 2005.

24. Martinou JC and Green DR: Breaking the mitochondrial barrier. Nat Rev Mol Cell Biol 2: 63-67, 2001.

25. Arnoult D, Gaume B, Karbowski M, Sharpe JC, Cecconi F and Youle RJ: Mitochondrial release of AIF and EndoG requires caspase activation downstream of Bax/Bak-mediated permeabilization. EMBO J 22: 4385-4399, 2003. 